\title{
Role-meanings as a critical factor in understanding doctor managers' identity work and different role identities
}

\author{
Rosalía Cascón-Pereiraa, Shiona Chillasc, Jerry Hallierb
}

\begin{tabular}{|c|c|}
\hline Date of deposit & [30 09 2016] \\
\hline Document version & Author's accepted manuscript \\
\hline Access rights & $\begin{array}{l}\text { (c) 2016, Elsevier B.V. This work is made available online in } \\
\text { accordance with the publisher's policies. This is the author } \\
\text { created, accepted version manuscript following peer review and } \\
\text { may differ slightly from the final published version. }\end{array}$ \\
\hline $\begin{array}{l}\text { Citation for } \\
\text { published version }\end{array}$ & $\begin{array}{l}\text { Cascón-Pereira, R., Chillas, S. A., \& Hallier, J. (2016). Role- } \\
\text { meanings as a critical factor in understanding doctor managers' } \\
\text { identity work and different role identities. Social Science and } \\
\text { Medicine, 170: pp18-25. }\end{array}$ \\
\hline $\begin{array}{l}\text { Link to published } \\
\text { version }\end{array}$ & https://dx.doi.org/10.1016/j.socscimed.2016.09.043 \\
\hline
\end{tabular}

Full metadata for this item is available in St Andrews Research

Repository at: https://research-repository.st-andrews.ac.uk/

\section{St Andrews Research Repository}




\title{
Role-meanings as a critical factor in understanding doctor managers' identity work and different role identities
}

\begin{abstract}
This study examines "identity work" among hybrid doctor-managers (DMs) in the Spanish National Health System to make sense of their managerial roles. In particular, the meanings underlying DMs experience of their hybrid role are investigated using a Grounded Theory methodology, exposing distinctions in role-meanings. Our findings provide evidence that using different social sources of comparison (senior managers or clinicians) to construct the meaning of managerial roles leads to different role-meanings and role identities, which are the source of the two established types of DM in the literature, the reluctant and the enthusiast. The contribution is twofold: our findings lead us to theorize DMs' identity work processes by adding an overlooked role-meaning dimension to identity work; and raise practical reflections for those who wish to develop enthusiast doctor managers.
\end{abstract}

Key words: Spain; Identity Work; Meanings; Clinical Directors; Role Identity; Attitudes to Managing.

\section{Introduction}

There is now a substantial body of research on how healthcare reforms shaped by a New Public Management rationale (NPM) in different OECD countries have impacted on doctors (Kirkpatrick et al., 2009, 2016). Duran-Arenas et al (1992), for example, note that contextual, organizational and individual levels of analysis are key to understanding participation in, or resistance to, healthcare management. They identify the role of the state, the structure of the medical profession and socialization processes as contextualising factors in accounting for patterns of, and attitudes to, healthcare management in different countries. Health policies of governments across the globe have emphasised market based drivers where notions of efficiency and effectiveness dominate, 
presenting significant challenges to the medical profession in responding to policy driven change (Waring and Bishop 2013). In addition, the exigencies of increased managerialism, and professional managers' continued inability to drive transformational change in healthcare settings has meant that doctors have been co-opted into management roles (Kirkpatrick et al 2016).

Research on these hybrid roles has been mostly located at the collective managementclinicians level of enquiry to provide a picture of the effect of healthcare reforms on doctors' professional autonomy, status, working patterns and to envisage the future of the profession (Waring and Currie, 2009; Fitzgerald and Ferlie, 2000; Numerato et al., 2012). This long running vein of research has also highlighted duality in professional and managerial values held by hospital doctor managers (DMs) towards management (e.g. Hoff, 1999; Martinussen and Magnussen, 2011; Waring and Bishop 2013). However, the socio-psychological processes underpinning doctors' identity work used to understand doctors’ responses to public service reforms have received less attention (Ashworth et al., 2013). In the efforts to classify DMs' responses to management as either enthusiastic or reluctant, the underlying processes that give rise to these separate stances remain largely unexplored.

Nevertheless a handful of studies have attempted to go further than categorizing the medical profession's broad responses to management with useful explorations of the individual experiences of doctors working in management, in an attempt to understand why some identify with the managerial role while others remain reluctant (e.g. Hallier and Forbes, 2005; Cascón-Pereira and Hallier, 2012; Lewellyn, 2001; Spehar et al., 2012; McGivern et al., 2015). The research has drawn attention to the individual experiences 
and antecedents of identification with the managerial role. However, in all these studies the question of how DMs develop the meanings attached to their role has been omitted as a key factor in the process of explaining variations in DMs' identities. Following Brown's (2015) ideas on meanings, this article starts from the premise that if we are to capture the nuances underpinning DMs' work-related identity construction, we need to focus on how they attach meaning to their roles and identities as clinical managers. Specifically, this article aims to develop existing knowledge of DMs’ identity work activities by attending to how role-meanings are constructed and how they influence identification. This aim is necessary because meanings as a constitutive element of identities and identity work have been neglected in the identity work literature, and fieldwork is required to explain the processes of meaning construction (Brown, 2015). Moreover, this research responds to an invitation from sociology of professions and public management literatures (Currie et al., 2010 and Ashworth et al. 2013, respectively) to incorporate knowledge from literatures in psychology and identity to understand the identification of hybrid clinicianmanagers with their managerial roles. If the ultimate goal is to engage doctors in management more effectively than hitherto and to explain how some doctors become enthusiastic managers while others remain hostile to managing, then exploring the meanings that inform identity work is a research priority. This view is supported by Weick (1995) who suggests that employees understand management as a social construction. That is to say, emotions, attitudes, identities and behaviours can be seen as a product of the meanings DMs attach to experiences. It follows that the role of meanings in DMs' identity work is central to uncovering the source of their attitudes to managing (Alvesson and Willmott, 2002).

To address these issues the article is structured as follows: the next section considers how inattention to DMs' identity work and role-meanings has impeded our ability to develop 
a satisfactory understanding of different role identities. Next, we reflect on how meanings have tended to be overlooked in the identity work literature, despite being acknowledged as central to both identity and identity work. Here we define and relate sensemaking, identification, identity, identity work and role-meanings, to contextualise and justify our research. We then describe our research procedure, including some background to the research context, and present findings on the different role-meanings constructed by DMs before commenting on the theoretical contribution to identity work literature in the context of health management research, and the implications of this research for practice.

\section{Missing meanings in doctor managers' identity work}

Over nearly two decades, academic examination of the impact of health policy changes on DMs has covered a wide range of outcomes, such as attitudes, autonomy, power, professional cohesion and hybrid roles (Numerato et al., 2012; Waring and Currie, 2009; Hoff, 1999; Martinussen and Magnussen, 2011). While some advances have been made regarding categorising DMs' stances, the understanding of how different responses develop are at best partial. In particular, these studies have plotted variation in doctors' enthusiasm for entering and working in management and classified them into two types, variously described: that is investors versus reluctants (Forbes at al., 2004); adoption of, or alienation from, management values (Martinussen and Magnussen, 2011); cosmopolitans versus locals (Spehar et al., 2012); organization-compatible versus profession-compatible (Hoff, 1999); incidental hybrids versus willing hybrids (McGivern et al, 2015).

Yet, only a few have addressed the causes of difference in DMs' stances. A case in point is macro-level studies which have been especially suited to determining some of the institutional, cultural and organizational factors that explain national differences in 
doctors' responses to health reform and management. Here, comparisons of northern and southern Europe (Kirkpatrick et al., 2009; Dent, 2006); and between Australia, England, New Zealand and China (Degeling et al., 2006) indicate that doctors' willingness to accept management roles is more nation-specific than originally supposed. Despite these advances, few attempts to explain differences in identification have been made at an individual level of analysis (Hallier and Forbes, 2005; Cascón-Pereira and Hallier, 2012; McGivern et al., 2015). McGivern et al. (2015) for instance, attribute DMs' varied stances to the initial role claiming that leads doctors to take up a manager role with their subsequent role being influenced by institutional logics. Cascón-Pereira and Hallier (2012) explain DMs' different stances in terms of the emotional experiences elicited by relationships with clinicians or senior managers. However, while these studies usefully reveal much about how different experiences affect DMs' self-definitions of group membership, the role-meanings that comprise what it is like to be a clinical manager, which can provide a unifying account for varied stances, is still to be described. Thus neglect of the meanings DMs' attach to their roles and the link between sensemaking and identity work has hampered efforts to explain different role identities.

\section{Meanings as the essence of identity work and sensemaking}

The lack of attention to DMs' role-meanings as a necessary starting place for shaping identity work and attitudes is difficult to explain. Since the 1950s, meanings have been seen as the source of all expressions of human experience including attitudes, behaviours and emotions (Kelly, 1955). Yet, research on DMs has concentrated on the outcomes of the process rather than on the meaning sources from which identities and attitudes develop. A more exact justification for focusing on role-meanings is provided if we turn to the related literatures on identity work and sensemaking (Weick et al., 2012). 
Identity has been defined as "the meanings that individuals attach to themselves" (Gecas, 1982:3; Brown, 2015:21) as they seek to address the question “who am I?” and identity work "as a set of active processes which serve to construct a sense of identity" as a sensemaking process (Sveningsson and Alvesson, 2003:1165). Moreover, identification has been understood to be a critical element of sensemaking. Indeed, Weick (1995:18) contends that "sensemaking and identity construction are simultaneous processes because making sense of the external environment is always self-referential”. Conceptualising sensemaking as a process, identity shapes behaviours and atittudes which in turn affect the image projected. The process involves relationships of power, incorporates emotions and is enacted in micro-level activities that often have disproportionate effects (Weick et al 2005). Notwithstanding the recognised relationship between the sensemaking process and identity work, meanings as the substance of identity work and the very fabric of the sensemaking process do not feature in identity research. Research on identity from the sensemaking perspective has focused on the discourses and narratives extrapolated from meanings (Brown, 2015) rather than meanings themselves. Brown, however, suggests that "much still needs to be done to understand in-depth how sensemaking connects to identities and the role of identity work in processes of external interpretation and meaning making” (2015:32). Hence, we surmise that a focus on meanings, in particular rolemeanings, as the micro-units that underlie these processes, aids understanding of identity construction in DMs. Moreover, Simpson and Carroll (2008) propose roles as a mechanism for identification, where roles may or may not become partially or even fully internalised as identities. Hence, role-meanings become the meanings constructed to give sense to a role and the micro-units that underlie role identification (see Figure 1). Rolemeanings are then the substance of the meaning-making process of identity construction. 
To understand the relationships between these concepts, we refer to the diagram in Figure 1 (own source). This recognizes meanings, in particular role-meanings, as the core ingredients with which sensemaking, and identification as a critical element of the sensemaking process, occur (Weick, 1995). Drawing on McInnes and Corlett's framework (2012) which classifies identity work through two dimensions, organizational discourses and interactions, Figure 1 proposes that role-meanings incorporate the influence of established antecedents for DMs' different responses such as social discourses, role models and institutional logics (McGivern et al., 2015), and interpersonal relations (Cascón-Pereira and Hallier, 2012; Hallier and Forbes, 2005), constituting the basis for constructing role-meanings. Figure 1 also shows that attitudes to the hybrid role are mediated by role-meanings and therefore become a source of DMs' identity work. We consider that these influences are not stable but depend on individuals' interpretation of the new role that is the active construction of meanings. Therefore, we position ourselves in the perspective that individuals' identities shift throughout the life course (Watson, 2008).

According to this framework, our focus on the micro-level analysis of role-meanings aims to achieve a grounded understanding of DMs' identity work, in particular how DMs develop role identities through sensemaking activities,to better fathom doctors’ responses to the health policy context.

\section{Research context and methodology}

The fieldwork was conducted in two teaching hospitals in Catalonia in Spain. At that moment, the Spanish National Health System (SNHS) offered universal health care coverage for all residents in Spain, providing publicly funded health services, mainly financed through national taxation (Garcia-Armesto et al., 2010). Both hospitals were theoretically sampled because at the time of research they were experiencing 
organizational changes driven by the NPM healthcare reform logic. This reform in Spain aimed to sustain the universal coverage model by increasing efficiency. Changes were based on transference of private sector management logic to public hospitals, including new hospital governance arrangements, cost-containment, the separation of the financing, purchasing and provision functions, the introduction of contractual relationships between these parties, and the creation of a competitive environment (Garcia-Armesto et al., 2010). These changes, particularly cost reduction, were only possible by involving middle-level doctors in management. Devolution of managerial responsibilities such as cost control, and performance assessment, took place without devolving decision-making and financial power (Cascón-Pereira et al., 2006).

In this context, we focussed on middle management hybrid doctor managers (DMs), the Spanish equivalent of UK Clinical Directors. Unlike the UK, where doctors become clinical directors for a fixed term, Spanish DMs often remain in the managerial role for the rest of their career. Another contextual difference was the absence, in Spain, of the discourses of NHS leadership that the UK government promoted through, for instance, the creation in 2001 of a Leadership Centre.

Despite contextual differences, similarities in the DM role under NPM initiatives among different Western European countries make the results of this study suitable for analytical generalisation. To maximise opportunities for comparison, we selected a privately managed public hospital (Hospital A) as a new form of hospital governance, and a publicowned and managed hospital (Hospital B). Both hospitals were similar in size and in specialties. However, in Hospital A the Medical Director was responsible to the organisation's CEO, and the Nursing Director reported to the Medical Director; in Hospital B, the Medical Director and Nursing Director were at the same level and reported to the CEO, appointed by the regional government. Also, although the job description for 
DMs in Hospital A included more management emphasis than in Hospital B, no differences were found when participants from each hospital were asked to describe their jobs. Most DMs retained a clinical role but not all. For instance, DMs providing specialist medical services retained a clinical role, but this was not the case for those attached to pharmacy or clinical analysis services.

A Grounded Theory (Glaser and Strauss, 1967) approach was adopted to guide the collection and analysis of data. In particular, we adopted the Straussian mode of this methodology (Strauss and Corbin, 1998) following systematic procedures to collect and analyse data. This methodology fitted our research aims because we wanted to gain grounded understanding of how doctors gave meaning to their managerial roles and identified with them, and in doing so to extend theory (Locke, 2001) on hybrid managerprofessionals' identity work. Although this article begins with theoretical sections and a conceptual framework represented in Figure 1, literature was not consulted until the selective coding stage, when we found a close fit between our analytical induction and the identity work literature and where we sought to extend theory by integrating our findings with extant research on DMs’ identity work.

Data were collected through two methods: in-depth semi-structured interviews and participant observation. Empirical material in this paper is drawn from interview data with DMs but in the main research project, medical directors, CEOs and nurse managers from both hospitals were also interviewed.

We interviewed 20 out of 34 DMs theoretically sampled; 10 at Hospital A and 10 at Hospital B; sample characteristics are described in Table 1. The remaining 14 DMs were not interviewed due to theoretical saturation (Strauss and Corbin, 1990:212), whereby no new or relevant data emerged regarding categories and relationships among categories were validated. Certain criteria used to select DMs emerged from the analysis thereby 
maximising opportunities to discover variations among concepts and allowing us to densify categories in terms of their properties and dimensions (Strauss and Corbin, 1990:201). Therefore, we compared DMs in the category "identification with the managerial role” and then looked for differences within this category by adopting a theoretical sampling strategy of maximum heterogeneity to explain differences in identification with the managerial role. Criteria used were: speciality, gender, previous management training, tenure in the hospital and in post, number of staff managed. We thought gender and previous training/socialization in management were important to account for differences in identification given previous research on professional identity (e.g. Pratt et al., 2006; Christie, 2006). Also, we compared DMs from different specialties, tenure in hospital and in number of subordinates, because these variables might influence role identification. To ensure appropriate selection, informal conversations with hospital staff and formal conversations with the Management Secretary who acted in both hospitals as "caretaker" of data (Taylor and Bogdan, 1992) were undertaken. The sampling design offered a strong foundation for elaborating theory: the same post allowed comparison among different sense-making processes, while the diversity of specialties, tenure, and type of hospital provided a sound basis for analytical generalization. Interviews were recorded and transcribed to ensure reliability (Eisendhardt, 1989). All interviews were conducted in Catalan or Spanish according to interviewee’s choice; and quotations in this article were translated into English by one of the authors. The interviews were framed by the following core question areas: how participants defined themselves in professional terms; experiences of the managerial role; content and meanings of the managerial role; role transition and relationships with senior management and subordinates. Also, participants were encouraged to explore anything they considered salient to their managerial experiences. 
Data analysis adopted constant comparison analysis where data gathering and data analysis activities were intertwined (Glaser and Strauss (1967). The data were initially organized into first-order codes such as "self-definitions” (e.g. doctor), “role-meanings” (e.g. centrality of clinical knowledge), “meanings of management” (e.g. distance from reality), "meanings of clinical work" (e.g. close to reality), “difficulties perceived” (e.g. level of autonomy) and “emotions” (e.g. belonging). These first-order codes drawn from the responses to the questions "How would you define yourself in professional terms by finishing the following sentence I am...?” (identity), "How would you define your role?” (role-meanings), and “What is “management” for you?” (meanings of management), were integrated into key categories (i.e. "meanings", “identities" and "attitudes to management”) and then interrogated for fit, recognising the possibility of contrasting and disconfirming data. Open coding proceeded into axial and selective coding (Strauss and Corbin, 1990), and analysis explored differences within the construction of rolemeanings. Next, we explored patterns in relationships between role-meanings and “identification with managerial roles”, using NVivo software to organise data. At the time of fieldwork, ethical approval was not required for research of this kind involving Spanish Health Service staff.

\section{Doctor Managers' shared professional identity and divergent Role-meanings}

In this section, we firstly define key similarities in the professional identity of our DMs . We then present different role-meanings underlying the two commonly found opposing types of DMs' role identities, labelled here 'enthusiastic' and 'reluctant'. Finally, we integrate our findings with extant identity work and health management research.

Consistent with recent research on hybrid roles in healthcare (Croft et al 2015, Mc Givern et al., 2015), our DMs strongly identified with their clinical role. They all described 
themselves as doctors, typically saying, 'it doesn't matter what you do, above else you are a doctor!' (P15)

Despite assuming the hybrid role, either as reluctants or enthusiasts, all participants were keen to distance themselves from the "manager" role. The words "manager" and “management” were applied solely to hospital senior managers (CEO and Medical Director), reinforcing a collective identity common in this 'heavily professionalised context’ (Currie et al 2010)

In addition to these common perceptions of "themselves" and 'the other', our findings also revealed different identification with the managerial role which allowed classification into enthusiastic and reluctant DMs. Surprisingly, none of the criteria used for the theoretical sampling (hospital type, tenure, gender, specialty, previous management training and number of directly reports) seemed to account for differences found in identification.

Initial exploration of differences revealed that DMs used a set of meanings to assemble their role identities by looking to different comparator groups. In each comparison DMs developed a meaning from assessing the comparison role against their managerial role, from which they constructed a DM role identity. These comparison roles were hospital senior managers, referred to as "managers", and clinicians. From the meanings attached to such role comparisons, different understandings of managing emerged. DMs identified with their managerial role to a greater or lesser extent, becoming enthusiastic or reluctant DMs respectively. We thus categorised DMs into two types according to identification with the managerial roles: reluctant DMs who did not identify with the managerial role and enthusiasts who did, consistent with previous research on hybrid roles (Hoff, 1999; Forbes and Hallier, 2004; McGivern et al., 2015). However, we add to this literature with 
a focus on the role-meanings from which each group of DMs developed role identities and understandings of managing.

Role-meanings and Role Identity developed when comparing with clinicians:

\section{Reluctant DMs}

In comparing enthusiast with reluctant DMs we discovered different sources for identification with the managerial role; distinguishing features were related to motives or attitudes towards managing but also attributable to the role-meanings developed in the role. Reluctant DMs developed their role-meanings by comparing themselves with the clinicians they managed or by reference to their previous job as consultants. In drawing upon these comparisons, the following meanings and properties of clinical management were developed: First, managing was seen as secondary to clinical work, easily disregarded in favour of clinical priorities, as the following participant declares:

“Management can always wait...and I can take my time to do it....but the patient can’t wait, he’s there and I have to attend him...” (P17)

Second, managing was seen as unpredictable, difficult to gauge and often beyond DMs' control. This excerpt exemplifies how reluctant DMs construct role-meanings in this dimension:

In clinical work it's just you and your ability. It's you and your unit who are the professionals in contact with the patient, and you are in charge of all this ... and moreover, you have the power to decide the appropriate treatment for each situation, understand? In comparison, well management.....management is not in our hands. in managing you cannot control anything...it’s not in our hands...it's stressful...I prefer being two mornings in the operating room, sweating and perspiring ....than having to organize all this chaos! (P12)

Thus, the managerial role equates to unpredictability and lack of control, generating feelings of stress and uncertainty (see Croft et al 2015). Relatedly, the boundaries of 
managing were not clear cut and hence responsibilities could become burdensome, illustrated by:

In my opinion ideal work is being a consultant with a good supervisor, isn't it? You only have to see patients, and then go home....but now, I have chaos and unlimited responsibility, so I go home and take work with me, and I can spend hours at home doing roster forms and planning staff holidays.(P1)

The medical role was perceived as recognizably ordered and linked to the hospital context, whereas the managerial role did not have such situational limits giving rise to potential inter-role conflict.

Such meanings were in stark contrast to those attributed to clinical work: that is vital and pressing, predictable, controllable and self-reliant, with clear responsibilities. With this set of role-meanings, clinical management was experienced not only as unpalatable but also stressful arising from instability, role conflict and ambiguity, incompetency, and lack of control. Reluctants tried to escape these pressures by sheltering behind feelings of selfreliance, security, self-confidence, self-efficacy, and belonging to a meaningful group of clinicians, as the following participant notes:

\footnotetext{
“I’m on call twice or three times a week...I haven’t stopped being on call because I need it...I need to do medical practice, it gives me the satisfaction and assurance that managerial work doesn't...and if I don’t succeed in doing this, I’ll return to my clinical position” (P17)
}

This need to undertake clinical work to compensate for the negative emotions that emerged from managing has also been identified in the case of nurses in hybrid positions (Croft et al., 2015) but interestingly role conflict disappeared when clinical work was removed. Analysis of these meanings reveals the importance of previous socialization in a role to enhance “feelings of control”. Doctors' careers traditionally imply long socialization in their medical roles which make them feel competent, confident and secure in clinical work, in essence creating a “comfort zone”. The comfort zone has been defined 
as a behavioural state within which a person operates in an anxiety-neutral condition, using a limited set of behaviours to deliver a steady level of performance, usually without a sense of risk (Bardwick, 1991). On the contrary, managing is fraught with uncertainty. If socialization is responsible for the construction of a comfort zone (Bardwick, 1991), longer socialization in management and isolation from clinical work for a period of time, may be capable of counteracting these meanings in those who need to feel in control within their work domain.

While reluctant DMs valued their clinical work, they were unable to internalize managerial roles, or even to lessen the aversion to such roles; they dis-identified with their managing role, defined themselves by their lost role as consultants, and developed negative attitudes to the whole notion of management. The importance of the comparator chosen to the type of meanings developed is illustrated in the next section, where we examine the very different meanings developed by enthusiastic DMs.

Role-meanings and Role Identity developed when comparing with senior managers:

\section{Enthusiast DMs}

One of the distinguishing features of DMs who were comfortable with their management role was that they described themselves as natural leaders using this term to purposefully differentiate themselves from “managers”. In feeling this way, often from an early age, they accepted their managerial role as a natural career evolution, with an appealing role identity. A male doctor for example, believed that he had inherited his leadership qualities from his father, saying,:

“In a course I attended I was called a 'born leader'....in fact, when I was a child, my father told me I looked like him because I was always bossing other children in the playground... I would even row with them for power in the playground... now I have a two year old child who does the same! (P16) 
Likewise a clinical director referred to his predisposition for leadership as the reason for entering management:

"Let’s see...I think it is innate ....there are people who are not interested in leading and there are others who are born for it, aren't there? I think I'm a born leader, then... What motivated me? I followed my instinct and my nature to fulfil myself...otherwise, I would have been incomplete”. (P18)

By self-defining as "leaders", enthusiasts were disposed to feel destined to improve the clinical services they managed. These DMs regarded leadership as a meaningful selfdescribing label that distinguished their tasks from those of senior management. When analysing their role-meanings, we found that their enthusiasm arose because, comparison with senior hospital managers instead of clinicians, developed distinctly more positive role-meanings than reluctants. From this comparison, enthusiasts' role identities were composed of meanings that were in their eyes quite distinct from hospital managers' roles. Emphatically, enthusiasts saw their DM role as "close to the realities" of healthcare because they continued to practice medicine. In comparison, they saw senior managers and management as out of touch, detached from day-to-day healthcare, and protected from the real dilemmas faced by clinicians, as the following quote exemplifies:

“Ah management....those fools...I don't know; they don't look as if they live in the real world...not at all in touch. Why? Because....let's see, I guess that they exist more in the hospital's macroeconomic world and they don't live in the day to day; they don't face the problems that we have to"(P7)

Relatedly, managing for enthusiasts depended on an understanding of advanced healthcare, whereas the senior management role was regarded as lacking the clinical knowledge required for the exercise of leadership and therefore capable only of making decisions based on economic criteria, for example: 
"I think that if we started attending and operating on men in this unit (Gynecology), they (senior management) wouldn't even notice, unless the costs increase”. (P18)

Third, enthusiasts' management efforts were directed at improving medical care in opposition to senior managers' roles which were perceived as driven by political interests and opportunism. One DM describes this opposition:

'I'm the patients' advocate and I stand up for their rights and if this contradicts what senior managers want from me, it's the patients' needs which'll win out... if they don't like it...f**k them, they can sack me... But they (senior managers)...they're only worried about satisfying the politician in charge’s desires not to lose their job!” (P16)

These role-meanings suggest that enthusiastic DMs see their unique value and source of power emanating from close functional proximity to the clinical process. To these DMs, hospital management required no specialist background or skills. In contrast, doctors’ involvement in running a day-to-day healthcare unit was seen as the source of their status.

\section{Role-meanings as the substance of DMs' identity work}

These examples of how different meanings for the DM role develop through comparisons with other social actors are nothing new for Social Categorisation Theory (Turner et al., 1987) or for theories of identity from a social psychological perspective, since role identity has been recognised as relational (Ashforth, 2001), or from a postructuralist perspective, since Alvesson and Willmott (2002:629) also recognise the process of “defining a person by defining others”. Indeed, our results support Turner et al.’s (1987) contention that individuals try to construct positive identities in their work domain. In particular, Turner et al. (1987) contend that a positive identity is relational rather than an intrinsic quality. They suggested social perceptions of similarity or difference are the single most important outcome of the self-identification process. As with our own findings, positive meanings are contingent on comparisons between one's own and 
selected other roles to determine which role features, if any, are meaningful. In pursuit of self-esteem, our DMs tend to accentuate difference from comparison groups that favours their own status, as happens with enthusiast DMs, or identify with their previous role that protects self-esteem as happens with reluctant DMs. However, our findings add that DMs' choice of comparison group determines the particular role-meanings that develop and also their final role identities. Hence, reluctant DMs did not identify with their managing role because they developed negative meanings from their comparison with the clinical role whereas enthusiasts' decision to compare their managing role with that of senior hospital managers gave rise to superior DM meanings, enabling them to identify with their managerial roles. Table 2 summarizes the key differences in the role-meanings developed by reluctant and enthusiast DMs and relates these differences to their role identities. Table 2 gives context to Figure 1 by showing differences between the two groups in terms of role-meanings. It is evident that reluctant DMs view the role in relation to their former role as a consultant, setting up negative attitudes towards the demands of management, in turn distancing DMs further from the role. In addition, reluctants see the DM role as removing autonomy and feel powerless and incapacitated by the manager role. In contrast, enthusiasts who see themselves as "leaders", more effective and informed than their senior management comparator group consequently embrace their role, viewing their contribution as positive and their patient advocate position as valuable. We suggest these findings are an important contribution in understanding manager-professionals' identity work that permits a better grasp of doctors' responses to general management models brought in by health policymakers.

\section{Discussion and Conclusion}


This article has attempted to shed light on DMs' different role identities by exploring the neglected area of role-meanings in doctor managers' identity work and in so doing, to contribute to theory on hybrid manager-professionals' identity work by attending to the role of meanings in the identification process. Studies on healthcare management have traditionally been analysed at the professional level, paying little attention to the microdynamics of identity work, or to the role of meanings within the identification process. Our research integrates knowledge from psychology and organization studies in the 'generative dance' suggested by Currie et al (2012) and contributes to the burgeoning literature on identity work in healthcare professions, considered at a micro-level of practice (Currie et al 2010; Croft et al 2015; McGivern et al 2015).

In Figure 1 we present a conceptual map of the identity work undertaken by DMs. Our findings indicate that role-meanings play an important part in DMs' identification with managerial roles. In particular, role-meanings work as the very fabric with which the sensemaking process of identification is developed and different role identities are constructed. Furthermore, role-meanings are proposed as the means by which institutional discourses and interpersonal relations with other social actors operate and influence role identities. By incorporating role meanings in the identity work process, Figure 1 adds to the understanding of how identities are constructed in hybrid professional-managerial roles. The findings add to research on the impact of public management reforms on managerial positions in healthcare and illuminate the importance of comparison groups in the construction of role-meanings, through which final role identities are developed. This model is a theoretical contribution and a starting point for future research on identity work in healthcare professions.

By drawing on identity work literature to integrate our grounded understanding of DMs' identification process, our study theoretically contributes to two areas of knowledge: 
identity work and health management research. Firstly, we consider how our study adds to the extant literature on identity work. Here, we relate our study to the general framework developed by McInnes and Corlett (2012), who suggest that identity work is comprised of two classifying dimensions: an ideational/discursive dimension in which identities are constructed by the influence of organizational and societal discourses on people's interactions; and an interpersonal dimension where the person's identity is repaired, maintained or revised by social interactions. Our results suggest that these dimensions of identity work are stated through role-meanings as shown in Figure 1. We therefore suggest role-meanings are an important way to understand influences on identity work. Accordingly, we propose that the influence on role identities of certain institutional logics and discourses such as managerialism, professionalism or leaderism (O’Reilly and Reed, 2011; Ford, 2006), pervasive in the hospital context, operates through the construction of particular role-meanings. This mechanism acknowledges that influences act differently and to different degrees. Institutional discourses may significantly shape managerial identities, but DMs moderate this influence through constructing different role-meanings. Likewise, as Figure 1 demonstrates, the influence of interpersonal relations on the development of role identities operates through the construction of role-meanings. In our findings, this seems to arise from not only choice or salience of a social group but the resulting evaluation of the role-meanings constructed through comparison. Accordingly, if the resulting role-meaning is positively valued because the source of comparison has been negatively assessed, identification will proceed. On the other hand, when the comparison role is highly prized, not only identification but also engagement with the current role will falter. Hence, role-meaning as a missed dimension in understanding identity work provides a deeper understanding of the basis of positive or negative values upon which the self-categorizations and social 
psychological processes of doctors in management (Hallier and Forbes, 2005) and also nurse managers (Croft et al., 2015) are manifest.

Secondly, our work extends theory on hybrid manager-professionals’ identity work by adding to the recent model developed by McGivern et al. (2015). This model explains differences between "incidental” and "willing” hybrids in terms of motivation to embrace the managerial role ("role claiming") and in terms of how hybrids influence other professionals ("role use"). Although there is an assumption in the literature that DMs share meanings of management, McGivern et al's model and our findings suggest that this is not the case. Here, we suggest role-meanings as an additional key dimension to distinguish among willing and incidental hybrids, illustrated in Table 2. The new dimension is consistent with the model, which recognizes the influence that institutional logic, described as “alternative social frames providing meaning to activity, conditioning sensemaking, action and identity” (Thornton et al. 2012, cited in McGivern et al, 2015:4) has on meanings. By incorporating DM's role-meanings in analysis of role identities, our case develops the model at a micro-level of analysis.

Although our main contribution is theoretical, several practical implications are also evident from the research. First, our findings aid understanding of the difficulties involved in training DMs. Recent studies in health management have begun to criticize the idea that doctors' resistance to becoming managers should be met with more training in general management and ‘leadership’ (Edmonstone, 2011; Greener et al., 2011). Indeed, our findings suggest that the obstacles to transforming doctors into eager managers are too complex to be simply overcome by further provision of leadership development programs. We argue that it is not a question of providing training but of how these programs are developed. Our findings do not rule out the need for training and 
development of DMs, but suggest attention to considering and dealing with doctors' rolemeanings as the principal source of their role identities.

For instance, Florent-Treacy (2009) recognizes the importance of identity work as a key component of leadership development programs for executives. Likewise, Ibarra and Petriglieri (2010) highlight the importance of identity play with provisional selves for subsequent identification. Our findings corroborate these suggestions with reference to enthusiasts with implications for leadership training programmes. In our case, enthusiasts had played with provisional selves as "leaders" derived from role models. Understanding leadership programmes in terms of socialization processes (van Mannen and Schein, 1979) or as experimental laboratories in identity (Florent-Treacey, 2009) where doctors can experiment with provisional selves as leaders, with appropriate role-models to support this activity, provide new ideas to frame these programs. For instance, cessation of clinical work during the program is recommended in the light of our findings. This measure may discourage reluctants from resorting to a clinical refuge in search of feelings of control and encourage them to move out of this comfort zone (Bardwick, 1991), by using role models other than consultants or clinical colleagues to construct role-meanings (see also Croft et al 2015 with reference to nurses’ emotional attachment to their role). The question nonetheless remains for further research as to how long this "isolation from clinical practice” might be necessary.

Second, given that higher levels of engagement by DMs have been associated with higher organizational performance (Ham and Dickinson, 2008), the reasons to engage doctors with management remain strong. In this regard, our findings suggest there are implications from identifying the managerial role with leadership. Extant literature has explored the impact of leadership discourses on managerial positions (Ford, 2006; O’Reilly and Reed, 2011). However, our case provided a distinct scenario since "leader" 
was not an imposed category but emerged as a label DMs used to distinguish themselves from managers. Hence, our results are instructive in terms of what happens when "leader" is adopted as a role-defining term. For enthusiasts, leadership was not just a semantic alternative to management. Rather, leadership became a highly evocative label that united role-meanings in such a way as to allow enthusiastic DMs to make sense of what they did and to integrate the managerial role into their core doctor identity. Accordingly, enthusiasts' self-description as clinical leaders cannot be considered as a faddish substitute to being called managers. The terms leader and leadership were used differently from the political and policymaker justification of NPM reforms as an evolution of managerialism or a leadership discourse as a means of connecting doctors with the formal management agenda (Martin and Learmonth, 2012; O’Reilly and Reed, 2011). In our study, leadership was never a meaningless concept (Storey, 2004), nor a rhetorical device constructed artificially, as studies on leaderism have noted (Learmonth, 2005). Instead, our findings suggest that leadership was used as a dialogic which enabled DMs to reconcile the daily ambiguity between clinical and management roles. In this way, leadership was less a particular style of management and more a separate ontological category that appealed to the enthusiastic DMs who did not wish to be depicted as managers (Parker, 2004). Instead self-categorisation as leaders became a way for DMs to enhance self-esteem and to position themselves as elite actors. This positioning can be conceived as part of the dynamic of intra-professional stratification in the medical profession mentioned by Numerato et al. (2012) as a more subtle reaction than the contradiction frequently framed in the professions literature between professionalism and management. We expect this finding to make public management audiences reflect on how to promote active engagement with leadership without imposing leaderism discourses. 
Notwithstanding advances in understanding DMs' identity work, because our results are exploratory, our findings raise several issues and limitations that would benefit from sustained future research. In particular, questions are raised on why DMs choose their particular comparator group, and what leads them to focus on certain roles (senior manager or consultant) to construct the role-meanings? Is it the lack of appropriate role models that leads reluctants to hold onto their former role as consultants? Further research is needed to respond to these issues. Social Categorisation Theory (Turner et al., 1987) might aid understanding of how particular social groups become salient for comparison. Also, a longitudinal approach might be useful to explore how professional and role identities change over time and if so, what motivates these changes and the associated evolution of role-meanings. Moreover, given that centrality of clinical identity seems important to obtain legitimate authority to manage (Croft et al., 2015; Spehar et al., 2014) and has also been considered as the basis for a medical educator role (Bartle and Thistlewaite, 2014), another question to be explored is the extent to which clinical identity is compatible with managerial identity or educational identity.

In conclusion, our focus on DMs' role-meanings has represented a potentially useful research direction within which to examine the process underpinning DMs identification with management roles. It has demonstrated that a focus on micro-level phenomena such as the construction of role-meanings can illuminate hybrid professional-managers' identity work process as a guide for future research.

\section{References}

Alvesson, M. and Willmott, H. (2002). Identity regulation as organizational control: producing the appropriate individual. Journal of Management Studies, 39, 619-44.

Ashforth B.E. (2001) Role Transitions in Organizational Life: An Identity-Based Perspective. Mahwah, NJ: Erlbaum. 
Ashworth, R.; Ferlie, E.; Hammerschmid, G.; Moon, M.J. and Reay, T. (2013) Theorizing contemporary Public Management: International and Comparative Perspectives, British Journal of Management, 24,S1-S17

Bardwick, J. (1991) Danger in the comfort zone: form Boardroom to Mailroom: How to break the entitlement habit that's killing American Business. American Management Association.

Bartle, E. and Thistlewaite, J. (2014) Becoming a medical educator: motivation, socialization and navigation. BMC Medical Education, 14,110-19.

Brown, A.D. (2015). Identities and Identity Work in Organizations. International Journal of Management Reviews, 17, 20-40.

Cascón-Pereira, R., Valverde, M. and Ryan, G. (2006) Mapping out devolution: an exploration of the realities of devolution, Journal of European Industrial Training, 30,129-151.

Cascón-Pereira, R. and Hallier, J. (2012). Getting that certain feeling: the role of emotions in the meaning, construction and enactment of doctor managers' identities. British Journal of Management, 23,130-44.

Christie, A. (2006). Negotiating the uncomfortable intersections between gender and professional identities in social work. Critical Social Policy, 26, 390-411.

Croft, C, Currie, G. and Lockett, A. (2015) The impact of emotionally important social identities on the construction of a managerial leader identity: A challenge for nurses in the English NHS, Organization Studies, 36, 113-31.

Currie, G.; Finn, R. and Martin, G. (2010) Role transition and the interaction of relational and social identity: new nursing roles in the English NHS, Organization Studies, 31, 941-61.

Currie, G., Dingwall, R., Kitchener, M., Waring, J. (2012). Let's dance: Organization studies, medical sociology and health policy. Social Science and Medicine, 74, 27380.

Dent, M. (2006). Post-NPM in public sector hospitals? The UK, Germany and Italy. Policy and Politics, 33, 623-36.

Duran-Arenas, L, Asfura, M. and Mora, J. (1992). The role of doctors as health care managers: An international perspective. Social Science and Medicine, 35, 549-555.

Edmonstone, J. (2011). The challenge of capability in leadership development. British Journal of Health Care Management, 17, 572-578. 
Eisenhardt, K.M. (1989). Building theories from case study research. Academy of Management Review, 14, 532-550.

Fitzgerald, L. and Ferlie, E. (2000). Professionals: Back to the future?. Human Relations, 53, 713-39.

Florent-Treacy, E. (2009). Behind the Scenes in the Identity Laboratory: Participants' Narratives of Identity Transition through Group Coaching in a Leadership Development Programme.INSEAD Working Paper.

Forbes, T.; Hallier, J. and Kelly, L. (2004) Doctors as managers: investors and reluctants in a dual role. Health Services Management Research, 17, 167-176.

Ford, J. (2006) Discourses of leadership: gender, identity and contradiction in a UK public sector organization, Leadership, 2, 77-99.

Garcia-Armesto, S., Abadía-Taira, M.B., Durán, A., Hernández-Quevedo, C. and BernalDelgado, E. (2010) Spain: Health System Review. Health Systems in Transition, 12,1-295.

Gecas, V. (1982). The self-concept. Annual Review of Sociology, 8,1-33.

Glaser, B.G. and Strauss, A.L. (1967). The discovery of grounded theory: strategies for qualitative research, Chicago: Aldine.

Greener, I. Harrington, B. Hunter, D. Mannion, R. and Powell, M. (2011). A realistic view of clinic-managerial relationships in the NHS:1991-2010, NIHR.

Hallier, J. and Forbes, T. (2005). The role of social identity in doctors' experiences of clinical managing. Employee Relations, 27, 47-70.

Ham, C. and Dickinson, H. (2008). Engaging doctors in leadership: what we can learn from international experience and research evidence, NHS Institute for Innovation and Improvement. Coventry: University of Warwick.

Hoff, T.J. (1999). The social organization of physician-managers in a changing HMO. Work and Occupations, 26, 324-51.

Hogg, M. and Terry, J. (2000). Social identity and self-categorization processes in organizational contexts. Academy of Management Review, 25, 121-140.

Ibarra, H. and Petriglieri, J.L. (2010) Identity work and play. Journal of Organizational Change Management, 3, 10-25.

Kelly, G.A. (1955/1991). The Psychology of Personal Constructs. New York: Routledge.

Kirkpatrick, I., Kragh Jespersen, P., Dent,M. and Neogy, I. (2009). Medicine and Management in a comparative perspective: the case of Denmark and England. Sociology of Health and Illness, 31, 642-58. 
Kirkpatrick, I., Kuhlmann, E., Hartley, K, Dent, M. and Lega, F. (2016), Medicine and management in European hospitals: a comparative overview. BMC Health Services Research, 16, 171-79.

Learmonth, M. (2005). Doing things with words: the case of "management" and “administration”. Public Administration, 83, 617-37.

Lewellyn, S. (2001). Two-way windows”: Clinicians as medical managers. Organization Studies, 22, 593-623.

Locke, K. (2001). Grounded Theory in Management Research. London: Sage Publications. Martin, G.P. and Learmonth, M. (2012). A critical account of the rise and spread of “leadership": The case of UK healthcare. Social Science and Medicine, 74,281-88.

Martinussen, P.A. and Magnussen, J. (2011). Resisting market-inspired reform in healthcare: the role of professional subcultures in medicine. Social Science and Medicine, 73, 193-200.

McGivern, G. Currie, G. Ferlie, E. Fitzgerald, L. and Waring, J. (2015). “Hybrid managerprofessionals' identity work: the maintenance and hybridization of medical professionalism in managerial contexts”. Public Administration, 93, 412-32.

McInnes, P. and Corlett, S. (2012). Conversational identity work in everyday interaction, Scandinavian Journal of Management, 28, 27-38.

Montgomery, K. (2001) Physician executives: the evolution and impact of a hybrid professional. Advances in Health Care Management, Vol.2, Bradford: Emerald.

Numerato, D., Dalvatore, D. and Fattore, G. (2012). The impact of management on medical professionalism: a review. Sociology of Health and Illness, 34, 626-44.

O’Reilly, D. and Reed, M. (2011). The grit in the oyster: Professionalism, managerialism and leaderism as discourses of UK public services modernization. Organization Studies, 32, 1079-101.

Parker, M. (2004). “Structure, culture and anarchy: ordering the NHS”. In M. Learmonth and N. Harding (Eds.),Unmasking Health Management. New York: Nova Science, pp.171-85.

Pratt, M. G., Rockmann, K. W., \& Kaufman, J. B. (2006). Constructing Professional Identity: the Role of Work and Identity Learning Cycles in the Customization of Identity among Medical Residents. Academy of Management Journal, 49, 235-62.

Simpson, B. and Carroll, B. (2008) Re-viewing "Role" in processes of identity construction, Organization, 15, 29-50. 
Spehar, I.; Frich, J.C. and Kjekshus, L.E. (2012). Clinicians’ experiences of becoming a clinical manager: a qualitative study. BMC Health Services Research, 12, 421-31.

Spehar, I., Frich, J.C. and Kjekshus, L.E. (2014) Clinicians in management: a qualitative study of managers' use of influence strategies in hospitals. BMC Health Services Research, 14, 251-61.

Storey, J. (2004). “Changing Theories of Leadership and Leadership Development”, in J.Storey (Ed.) Leadership in Organisations: London: Routledge.

Strauss, A. and J. Corbin (1990). Basics of qualitative research: Grounded Theory procedures and techniques. Sage, Newbury Park.

Sveningsson, S. and Alvesson, M. (2003). Managing managerial identities: organizational fragmentation, discourse and identity struggle, Human Relations, 56, 1163-93.

Turner, J.C., Hogg, M.A.,Oakes, P.J., Reicher, S.D. and Wetherell, M.S. (1987). Rediscovering the Social Group: A Self-categorization Theory.Oxford: Blackwell.

van Mannen, J. and Schein, E.H. (1979) Toward a theory of organizational socialization. In B.M. Staw and L.L. Cummings (Eds.) Research in Organizational Behavior, Vol.1, 209-64.

Waring, J. and Currie, G. (2009). Managing expert knowledge: Organizational challenges and managerial futures for the UK medical profession. Organization Studies, 30, 755-78.

Waring, J. and Bishop, S. (2013) McDonaldisation or commercial re-stratification: Corporatization and the multimodal organisation of English doctors. Social Science and Medicine, 82, 147-155.

Watson, T.J. (2008) Managing Identity: Identity Work, Personal Predicaments and Structural Circumstances, Organization, 15, 121-43.

Weick, K.E. (1995). Sensemaking in organizations, Thousand Oaks: Sage Publications Ltd.

Weick, K.E., Sutcliffe, K. and Obstfeld, D. (2005) ,Organizing and the process of sensemaking, Organization Science, 16, 409-21. 